\title{
Visible and infrared imaging spectroscopy of paintings and improved reflectography
}

\author{
John K. Delaney ${ }^{1 *}$, Mathieu Thoury ${ }^{1,3}$, Jason G. Zeibel ${ }^{2}$, Paola Ricciardi ${ }^{1,4}$, Kathryn M. Morales ${ }^{1}$
} and Kathryn A. Dooley ${ }^{1}$

\begin{abstract}
Background: Imaging spectroscopy, the collection of spatially co-registered images in many contiguous spectral bands, has been developed for remote sensing of the Earth utilizing reflectance or luminescence. In this paper we summarize findings on the application of imaging spectroscopy to works of art in order to identify and map artists' pigments, improve the visualization of preparatory sketches, and identify non-original material.

Methods: Two types of novel hyperspectral cameras, one operating from the visible to near-infrared (VNIR, 400$900 \mathrm{~nm}$ ) and the other in the shortwave infrared (SWIR, 950-1700 nm), have been used to collect diffuse reflectance spectral image cubes from a variety of paintings. The resulting cubes (400-1700 nm, 310 spectral bands) were calibrated to reflectance and the resulting spectra compared with point-based spectra collected with a fiber reflectance spectrometer (350-2500 nm). In addition, a calibrated multispectral camera (600-950 nm, eight spectral bands) was used to obtain luminescence spectral image cubes after exciting paintings at blue wavelengths.
\end{abstract}

Results: False-color images obtained from the SWIR imaging system are shown to give improved visualization of changes from paintings having large and complex reworkings, e.g. Pablo Picasso's The Tragedy (1903). False-color images and reflectance spectra allowed definitive identification of restoration in a late 13th century Sienese painting that cannot be seen by traditional infrared reflectography. Spectral image processing on the reflectance image cubes have been used to identify the primary pigments or pigment mixtures. For example, the primary pigments and their distribution in Picasso's Peonies (1901) was determined and compared with $\mathrm{x}$-ray fluorescence (XRF) analysis and scanning electron microscopy-energy dispersive $x$-ray spectroscopy (SEM-EDS).

Conclusion: The results show that the combination of both the SWIR reflectance data and the luminescence data provides a more robust ability to assign the pigments than with visible spectroscopy alone. Also highlighted is the utility of reflectance imaging spectroscopy in the SWIR region to better reveal specific paint changes, including changes in the drawings and markings made by the original artist, or changes made by a subsequent conservator such as a fill.

Keywords: Imaging spectroscopy, Reflectance spectroscopy, Pigment mapping, Infrared reflectography

\section{Background}

The conservation of a painting requires an understanding of the materials (pigments and binders) and construction

\footnotetext{
*Correspondence: j-delaney@nga.gov

${ }^{1}$ National Gallery of Art, 4th and Constitution Avenue NW, Washington, DC 20565, USA

Full list of author information is available at the end of the article
}

methods used by the artist. There are numerous analytical methods used today that provide a wealth of detailed information about the materials used as well as the stratigraphy of the paint layers. These methods, such as SEM-EDS, high-performance liquid chromatography, and transmission-mode mid-IR spectroscopy, all require dispersed samples (scraping from the paint surface) or paint cross-sections. While advances in technology and

\section{Springer}

(c) 2016 Delaney et al. This article is distributed under the terms of the Creative Commons Attribution 4.0 International License (http://creativecommons.org/licenses/by/4.0/), which permits unrestricted use, distribution, and reproduction in any medium, provided you give appropriate credit to the original author(s) and the source, provide a link to the Creative Commons license, and indicate if changes were made. The Creative Commons Public Domain Dedication waiver (http://creativecommons.org/ publicdomain/zero/1.0/) applies to the data made available in this article, unless otherwise stated. 
the development of new protocols by conservation scientists have minimized the sample size needed, the taking of samples is still required. Even though these methods provide the most detailed chemical information about the materials used, they cannot be used across the entire painted surface because the number of samples allowed is limited.

One method conservators use to gather information across an entire painted surface is infrared reflectography. Infrared reflectography is the use of infrared radiation to penetrate below the surface of paint and visualize compositional paint changes and preparatory sketches [1]. The resulting images are called infrared reflectograms and can also provide information on the evolution of the composition and construction methods. Infrared reflectography is often implemented such that the reflected light is collected over a wide spectral range (i.e. broadband) in the near-infrared (NIR, 750-1000 nm) and shortwave infrared (SWIR, 1000-2500 nm). The amount of chemical information that can be obtained in this situation is quite limited because the gray-scale values in the reflectogram are an average of the reflected light intensity over such a large spectral range [1]. In comparison to broadband reflectance imaging, the narrowing, and shifting of the spectral band used to examine works of art (through the use of either optical filters or a spectrometer), changes the optimal contrast of the paint, and preparatory drawings may be better visually separated from other paint layers [1].

In order to actually identify chemically distinct materials such as pigments (both organic and inorganic) and paint binders, conservators and conservation scientists have become interested in adapting chemical imaging methods to acquire information on the macroscale. Chemical imaging methods can also be used to supplement and extend the observations made from site-specific analyses and guide the selection sites for sampling. Most of the imaging-based methods have been developed from successful, site-specific, in situ analysis methods that do not require samples. These include reflectance [2-4], luminescence [4, 5], and $x$-ray fluorescence (XRF) [6] spectroscopies. Reflectance and luminescence spectroscopies provide information about electronic transitions [5, 7-13]. Reflectance spectroscopy in the SWIR provides information about vibrational transitions, which are mostly overtones and combination bands whose fundamental transitions occur in the midIR. These features are often related to functional groups like hydroxyl $(-\mathrm{OH})$ and carbonate $\left(-\mathrm{CO}_{3}\right)$ [7]. Absorption features from organic materials like the paint binding media, including the amide groups of proteins and lipid bands of oils and waxes, can also be observed [14] and even used to map their spatial distribution $[15,16]$.
The spectral resolution needed for identification and mapping varies across the spectral regions. In the visible range, many of the electronic transitions from pigments (i.e., blues, greens and earths) are slowly varying with wavelength, implying that a low spectral resolution can be used. However, to discriminate between pigments having sharp transition edges, such as red and yellow semiconductor pigments, a resolution of $<5 \mathrm{~nm}$ may be necessary. In the SWIR region, the required resolution should be $<10 \mathrm{~nm}$ in order to resolve the narrow vibrational bands associated with some binding media [1416]. X-ray fluorescence, in contrast, provides information on the elemental composition of materials and allows one to infer the possible colorants present [17]. Since many of the pigments used are inorganic materials, the use of $\mathrm{XRF}$ spectroscopy in conservation is widespread.

Efficient macroscale imaging of paintings using line-scanning imaging spectrometers $[2-4,15,16]$ or filter-based imaging systems $[5,10,18]$ has allowed conservation scientists to collect reflectance and luminescence images of paintings in the visible $(400-750 \mathrm{~nm})$, NIR, and SWIR. Using highly sensitive focal plane arrays, the images can be acquired under lighting conditions suitable for examination of paintings and even illuminated manuscripts $[15,18]$. Collection rates are typically on the order of a few minutes to scan an area of 640 by 640 spatial pixels in 150-300 spectral bands [2, 4, 15, 16]. In contrast, XRF imaging spectroscopy has been implemented using a raster scanning method, which provides detailed information about the elements used and in some cases the way they are layered within a work of art. These XRF scans can take many tens of hours to complete depending on the size of the painting [19].

The chemical imaging techniques discussed above are types of imaging spectroscopy or hyperspectral imaging. In this paper we show the application of imaging spectroscopy to study paintings on canvas and wood panels. The first example uses imaging spectroscopy in the visible and SWIR regions to map and help identify the primary colorants used in Pablo Picasso's Peonies. In the next examples, imaging spectroscopy in the SWIR helps provide detailed information concerning the underdrawings and paint changes in heavily re-worked paintings, and what areas are likely original material in paintings that have undergone restoration prior to modern conservation practice.

\section{Experimental}

Reflectance Spectroscopy - Imaging and Point-based Systems: The hyperspectral reflectance imaging cameras and processing methods have been previously described [4] and are only briefly summarized here. The visible-to-near-infrared (VNIR) imaging spectrometer 
(SOC-730VNIR, Surface Optics Corporation, CA) is a slit-based hyperspectral sensor that uses a transmission grating spectrometer (Specim Corp, Finland). The spectral range is $417-973 \mathrm{~nm}$ with a spectral sampling of $2.25 \mathrm{~nm}$ giving 240 spectral band images. A rotating scan mirror is used to sweep out one spatial dimension of the hyperspectral image cube, giving a final image size of 640 by 640 -spatial pixels by 240 spectral image bands. An integration time of $120 \mathrm{~ms}$ is used, giving an acquisition time of $77 \mathrm{~s}$ per cube. The first SWIR imaging spectrometer used for the two Picasso paintings is also a slit-based, scanning system that uses a grating spectrometer for wavelength dispersion (SOC-720SWIR, Surface Optics Corp). A 640 by 512 pixel InGaAs focal plane array (640SDV, Sensors Unlimited, NJ) is used as the detector array. The spectral range of the detector is from 960 to $1810 \mathrm{~nm}$ with a $10 \mathrm{~nm}$ spectral sampling, giving $85 \mathrm{spec}-$ tral band images. An integration of $33 \mathrm{~ms}$ per line gives an acquisition time of $22 \mathrm{~s}$ per image cube. The second SWIR hyperspectral camera is similar, although a more sensitive InGaAs array (640HSX-1.7RT, Sensors Unlimited, NJ) was used along with a spectrometer having $3.4 \mathrm{~nm}$ sampling, giving 209 spectral bands from 967 to $1680 \mathrm{~nm}$. A large white Spectralon ${ }^{\circledR}$ panel is used to flatfield the image cubes, and two in-scene black and white standards are used in all cases to calibrate the image cubes to reflectance. For the Picasso paintings studied, illumination was done using 750-W tungsten halogen lamps often employed for infrared reflectography [1, 4], and 125-W lamps were used for the Sienese painting. The cubes are spatially registered together using a rotation and translation mapping function whose parameters are defined by a series of manually determined tie points. This calibration and registration process yields a spectral image cube having usable information from 420 to $1660 \mathrm{~nm}$ in 310 spectral band images. The SWIR image cube was adjusted in gain to match the VNIR image cube at $960-970 \mathrm{~nm}$. While this corrected the majority of the offsets, some small deviations can be observed, likely due to small residual errors from scattered light.

To determine a basis set of reflectance spectra that describe the components present (i.e. endmembers), the image cube was processed using hyperspectral algorithms developed for the analysis of remote sensing data [20] and found useful for analyzing image cubes of paintings and manuscripts $[4,15,16,18]$. Because of the large number of reflectance spectra in the image cube, multivariate statistics were used to reduce the dimensionality of the data. To do this, principal component (PC) analysis was used to determine the diversity of the image cube, convex geometry was used to find the spectrally pure pixels, and then these pixels were manually clustered in PC space. Once the endmember spectra were determined, the spectral mapping algorithm was used to map each endmember. The algorithm for the mapping determines the angle between each endmember spectrum and the spectrum of each spatial pixel in the image cube. Using a threshold angle determined from examination of the histogram of angle values, a thresholded map is constructed to show where spatial pixels have reflectance spectra that well match that of the reference endmember spectrum. Using reference reflectance spectral databases of known artist pigments and previously identified spectral features of artist pigments, the endmember spectra were assigned to pigments when possible.

Fiber optics reflectance spectroscopy (FORS): FORS was performed on single points using a fiber spectroradiometer (Field Spec3, ASD Inc.) operating from 350 to $2500 \mathrm{~nm}$ [4]. The spectral resolution was $<3 \mathrm{~nm}$ in the VNIR range and $<10 \mathrm{~nm}$ in the SWIR. The sampled area was approximately $3 \mathrm{~mm}$ in diameter, and the acquisition time for each spectrum was shorter than $4 \mathrm{~s}$. Light levels were kept below approximately $4000 \mathrm{~lx}$ for these measurements. The spectrometer was calibrated using a white Spectralon ${ }^{\circledR}$ standard.

X-ray Fluorescence (XRF) Spectroscopy: XRF analyses were performed with a Röntec ArtTAX $\mu$ XRF spectrometer equipped with a rhodium $\mathrm{x}$-ray tube, helium flush and capillary optic lens with a diameter of $60 \mu \mathrm{m}$. The $\mathrm{x}$-ray tube voltage was $50 \mathrm{kV}$, the current was $200 \mu \mathrm{A}$, and the integration time was $200 \mathrm{~s}$. XRF data were interpreted using traditional methods, that is, the presence of pigments was inferred from the elements detected, the appearance of the locations examined, and the attribution of the work of art.

Luminescence Imaging Spectroscopy: As previously described $[4,5]$, an illumination and multispectral camera system assembled in-house, operating from 650 to $950 \mathrm{~nm}$, was used to obtain image cubes calibrated to relative radiance. Excitation illumination was done using two Kodak Ektagraphic III AT carousel slide projectors (OSRAM $300 \mathrm{~W}$ EXP bulbs) equipped with F/D 2.5, $152 \mathrm{~mm}$ Buhl optical lenses set up at 45 degrees from the normal of the painting at a distance of approximately $3.6 \mathrm{~m}$. The excitation bandpass was $380-520 \mathrm{~nm}$ defined by $50 \mathrm{~mm}^{2}$ Kron/Cousins B astronomy filters inserted into the two slide projectors. The multispectral camera system consists of a low-noise, 4-megapixel Si CCD camera (QImaging Retiga 4000R), outfitted with an F/D 2, $25 \mathrm{~mm}$ effective focal length hyperspectral lens (Coastal Optics). Spectral interference band pass filters (FWHM $40 \mathrm{~nm}$, Andover Corporation) were used to create the image cube of seven spectral bands. An in-scene calibration method was used to convert the image intensities to relative spectral radiance, using a cadmium pigment target whose spectral emission had been previously measured using the ASD spectroradiometer. 


\section{Results and discussion}

The paintings studied with the visible and SWIR imaging spectrometers include Pablo Picasso's Peonies, painted in oil on hardboard in 1901. The hardboard absorbs the oil more than a prepared canvas, thus giving a matte visual appearance. The Tragedy, painted in 1903, is from Picasso's Blue Period and is painted on a wooden panel. The third painting imaged is titled Maestà or Madonna and Child with Four Angels, and is a late 13th century Sienese panel painting attributed to a follower of Duccio di Buoninsegna. In each case the paintings were imaged using either both the VNIR and SWIR hyperspectral imaging cameras or just the SWIR camera. Each of these cameras consists of a whiskbroom-scanning mirror in front of a relay lens (fore optic), a slit and a transmission-grating spectrometer (Fig. 1). The formation of the image-cube is done using the scan mirror to sweep the image of the painting across the slit of the spectrometer, thus building up a slice of the cube one line at a time. This approach omits the need to slide the camera in front of the painting surface as is done in most systems [2,3] and provides for a compact system.

\section{(A) Mapping and identification of the pigments in Picasso's Peonies}

Two hyperspectral image cubes were collected of Picasso's Peonies using the VNIR and SWIR hyperspectral cameras (Fig. 2). The spectral processing was performed as previously described [4] and summarized in the "Experimental" section. The processing yielded eight reflectance spectral endmembers that were found to describe the painting well, as shown by the mapping results and endmember spectra in Fig. 2b and c. Comparison of endmember spectra with reference library spectra of minerals and artist pigments previously compiled by the USGS, CNR-IFAC [21, 22], as well as in-house

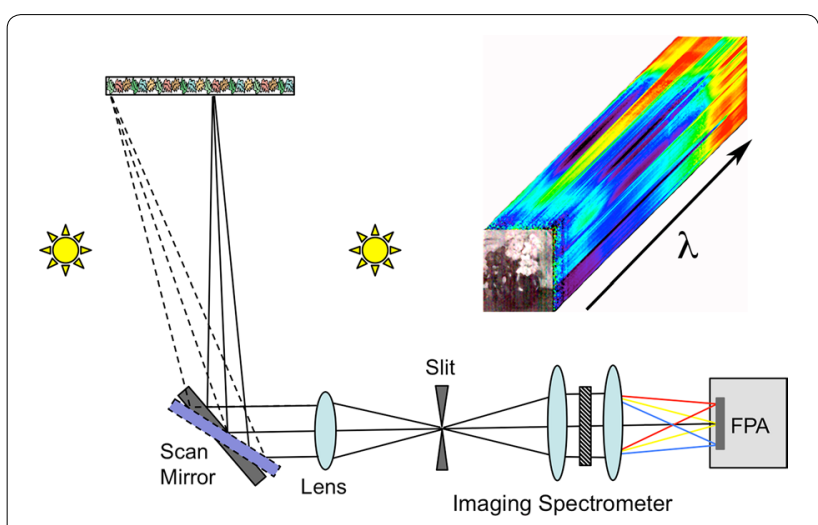

Fig. 1 Block diagram of the type of hyperspectral imaging camera with scan mirror used to collect the image cubes from the paintings analyzed in this study libraries and published papers, reveals the following: Prussian blue (endmember spectrum \#6 in Fig. 2c) was used for many of the darker features that make up the rough sketch of the vase, leaves, and the outline that separates the tabletop from the wall. Prussian blue is identified spectrally by the characteristic strong absorption due to a charge transfer band from 700 to $1200 \mathrm{~nm}[4,10,11]$. The map shows cobalt blue (endmember \#3) was used for most blue areas on the wall in the background. The assignment of cobalt blue can be made from absorption bands in the visible and the broad absorption in the near infrared from $\sim 1200$ to $1500 \mathrm{~nm}$ which originate from the ligand-field transitions between the $\mathrm{d}-\mathrm{d}$ orbitals of Co(II) in a pseudo-tetrahedral configuration $[4,8]$.

Emerald green (endmember \#2) was likely used to paint much of the vase itself and the green passages on the wall. The assignment of emerald green is made by the broad, characteristic absorption in the SWIR (700 to $1000 \mathrm{~nm}$ ). It is also possible that Prussian blue was mixed with a yellow which would achieve a similar spectral shape. However, $\mathrm{x}$-ray fluorescence spectroscopy detected arsenic (As) and copper $(\mathrm{Cu})$ at sites in the vase and wall (Fig. 3a), which supports the assignment of the green spectral endmember as emerald green. Finally the brown table is well represented by endmember \#4 which has a small red transition edge at $590 \mathrm{~nm}$ suggestive of vermilion [4, 7]. The NIR spectral shape of endmember \#4 is closest to Prussian blue or emerald green, the latter making more sense to achieve the brownish appearance, although XRF was not collected to confirm this assignment.

Spectral endmember \#5 (spectrum denoted with a black line in Fig. 1c) maps to the white flowers and was found to lack the narrow absorption feature at $1447 \mathrm{~nm}$ characteristic of the hydroxyl band of lead white [4, 9]. This indicates that zinc white or titanium white were possibly used. FORS spectra taken at sites in the white flowers have a sharp reflectance transition edge at $380 \mathrm{~nm}$, which is consistent with zinc white and not lead or titanium white [9]. This was confirmed by XRF measurements that showed the presence of $\mathrm{Zn}$ in the white flowers [23] (Fig. 3b).

Two endmember spectra represent red paints that make up the red flowers. Endmember spectrum \#7 in Fig. 1c has a sharp transition edge with an inflection point at $598 \mathrm{~nm}$, which is suggestive of vermilion [4]. Vermilion is found to have a rather sharp transition edge with an inflection point which occurs between $\sim 580$ and $600 \mathrm{~nm}$ and a FWHM <40 nm [4, 7]. The red endmember spectrum \#9 has an inflection point at $608 \mathrm{~nm}$ and a broader transition edge, which suggests an organic red-lake colorant [4]. The endmember of the 'pure' yellow color has a single transition edge at $518 \mathrm{~nm}$ and as such can be assigned to several possible pigments (e.g. 


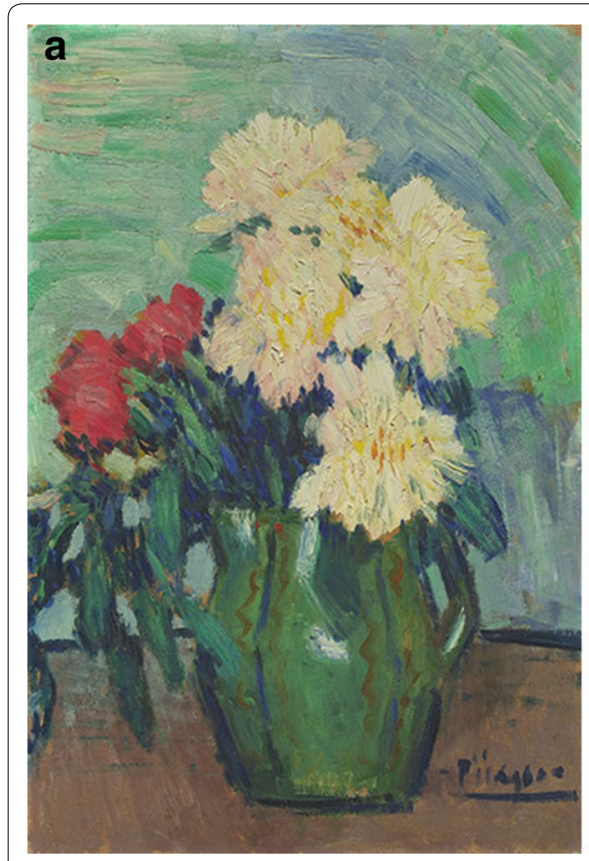

b

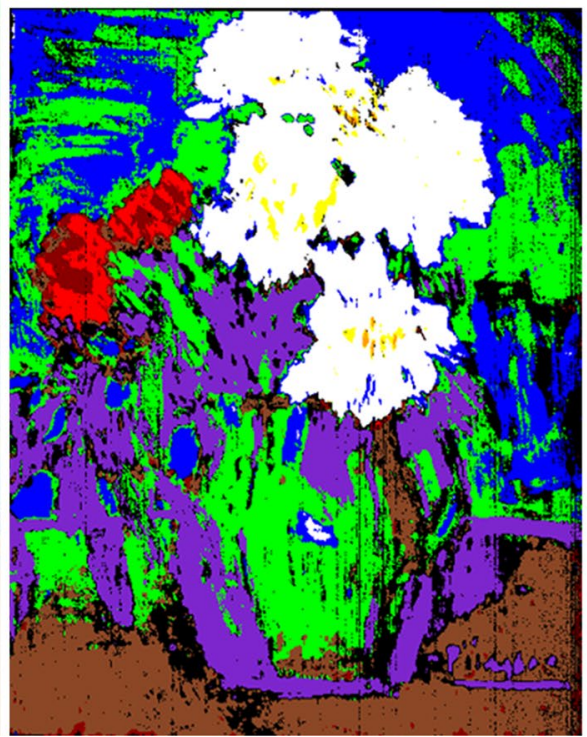

C Endmember Collection Spectra

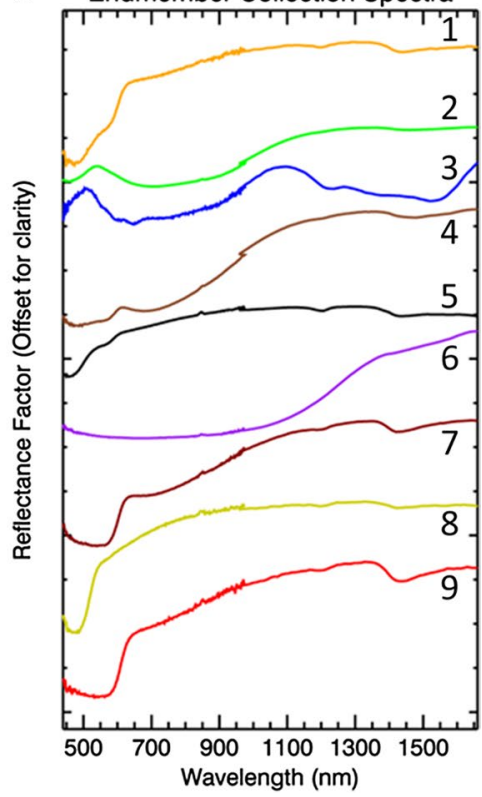

Fig. 2 Results from reflectance imaging spectroscopy of Pablo Picasso's Peonies (1901). Gift of Mrs. Gilbert W. Chapman, 1981.41.1, National Gallery of Art, Washington DC. a Color image. b False-color image showing the locations to which the spectral endmembers map. c Plot of endmember spectra, assigned to (1) cadmium yellow and vermilion, (2) emerald green, (3) cobalt blue, (4) "brown paint," (5) zinc white, (6) Prussian blue, (7) vermilion, (8) yellow (zinc), (9) red dye

cadmium yellow, chrome-containing yellow). The endmember spectrum represented by dark orange (\#1) maps to the stamens of the white flowers and has two reflectance transition edges, near $\sim 505$ and $587 \mathrm{~nm}$. These two transition edges suggest the presence of two pigments, a yellow and a red, to make the orange. The identity of the pigments in this region could be cadmium pigments, chrome or zinc yellows, vermilion, and/or lead chromate. When only simple S-shaped transition edges are present in the reflection spectra, identification of pigments from reflectance spectroscopy alone is often difficult. However, maps can be made showing the spatial distribution of the unknown composition and then point analytical methods, such as x-ray fluorescence, Raman, or reflectance mid-IR spectroscopies, can be employed to help in the identification. Other forms of in situ spectroscopy can also be used, for example, fluorescence emission by a pigment is often used as a visual clue to suggest the use of a dye. In this study, luminescence imaging spectroscopy is used to recover not only the spatial information of the emitted fluorescence but also the spectral shape of the emission spectra. In essence, it is the same experimental arrangement as hyperspectral reflectance imaging, but because of the low quantum efficiency of most dyes $(<10 \%)$, multispectral imaging as opposed to hyperspectral imaging is often employed. Blue light was used as the excitation source, and emission images were collected every $50 \mathrm{~nm}$ from 650 to $900 \mathrm{~nm}$. False-color images show where emission is present (see Fig. 4b). Luminescence signal is measured in the dark orange stamens of the white flowers, portions of the red flower petals, and to a lesser extent the white flower petals. Little or no luminescence is detected in the relatively pure yellow areas of the flowers. Using in-scene known luminescence standards $[4,5]$ allows the luminescence image cube to be calibrated to relative spectral radiance. This procedure allows for the comparison of emission spectra from each of these areas. The emission spectrum from the white flower petals (spectrum \#1 in Fig. 4c) decreases from 650 to $900 \mathrm{~nm}$, characteristic of zinc or lead white in a paint binder such as oil $[4,5,12,13]$. Emission spectrum \#2 from the red flower petals shows a similar trend. Because the emission is more intense in the red flowers than the white flowers, it is likely that the emission is from an additional red lake rather than only white pigments. XRF measurements from the luminescent regions of the red petals detected less $\mathrm{Zn}$ than in the luminescent white petals, suggesting less zinc white and indirectly supporting the presence of a red dye [23]. Finally, a redshifted emission maximum is observed from the orange stamens of the white flowers (see spectrum \#3). This has a weak but identifiable emission maximum that varies between 750 and $800 \mathrm{~nm}$. This large spectral shift in the emission spectra of $\sim 250 \mathrm{~nm}$ is indicative of emission 

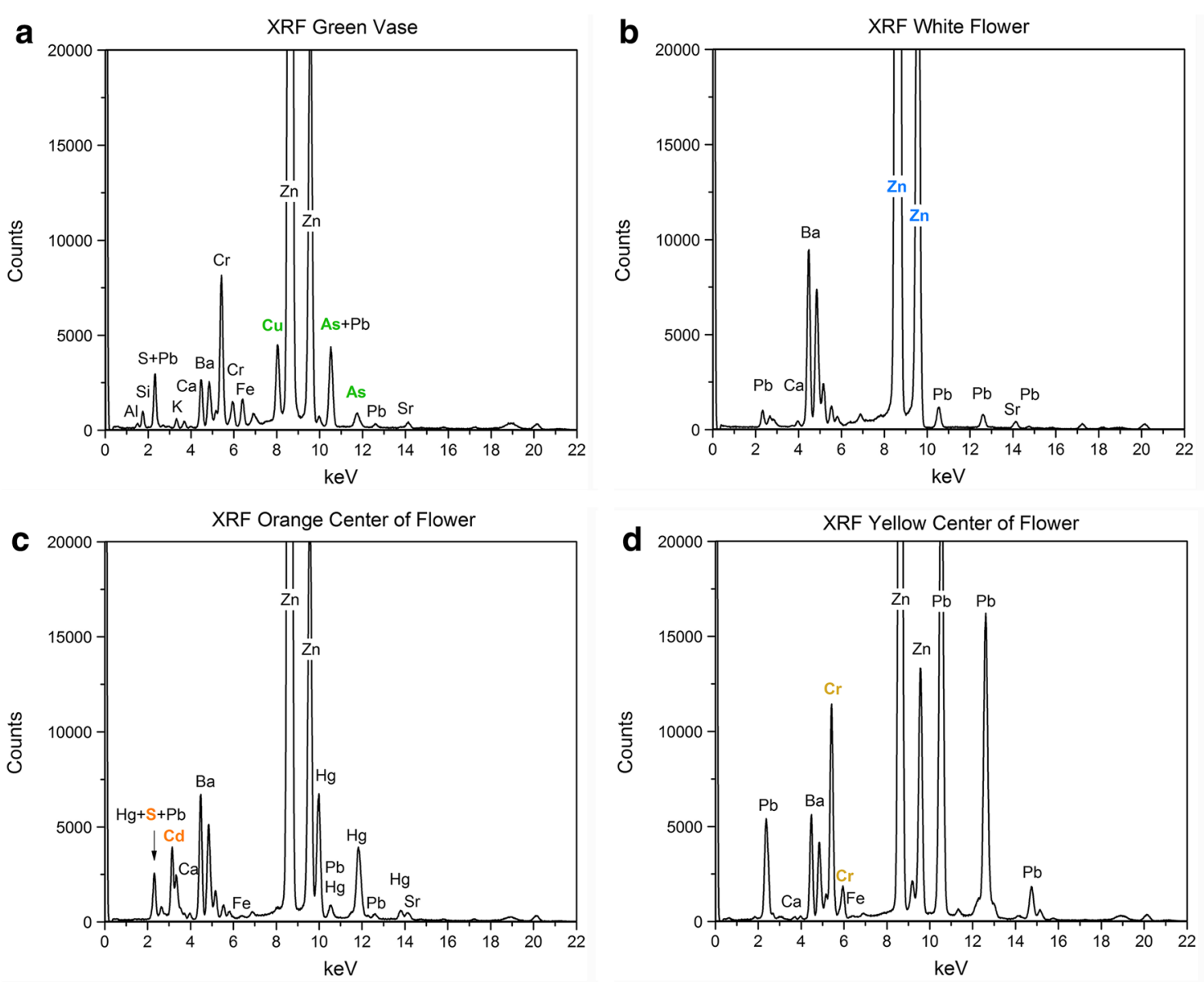

Fig. 3 Results from x-ray fluorescence point analysis of Picasso's Peonies. a XRF spectrum from the green vase showing elemental evidence for copper and arsenic (likely emerald green). b XRF spectrum from the white flowers showing evidence for zinc white. c XRF spectrum from the orange stamens showing evidence for cadmium pigments and vermilion. $\mathbf{d}$ XRF spectrum from the yellow areas of the flowers showing elemental evidence for a chromium-containing pigment

from low-lying trap states of a semiconductor, in this case likely from cadmium yellow or orange [5]. A prior detailed study found a correlation between the luminescence emission maximum and the wavelength of the reflectance transition edge for pigments [5]. Using these findings, an emission maximum between 750 and $800 \mathrm{~nm}$ is likely to have a reflectance transition edge between approximately 500 and $550 \mathrm{~nm}$, suggesting a yellow $\mathrm{Cd} / \mathrm{S} / \mathrm{Se}$ pigment was possibly used. XRF point analysis of an orange site on the lower flower reveals $\mathrm{Cd}$ and $\mathrm{Hg}$, consistent with a $\mathrm{Cd}$-containing pigment and vermilion (Fig. 3c). The reflectance spectra from these orange stamens (see endmember \#1 in Fig. 2c) have two inflection points, one at $\sim 505 \mathrm{~nm}$ and another at $587 \mathrm{~nm}$ as noted above, thus consistent with cadmium yellow and vermilion. XRF measurements of the yellow areas that had litthe or no fluorescence revealed no cadmium, but instead chromium $(\mathrm{Cr})$, suggesting the presence of a chromiumcontaining yellow (Fig. 3d).

\section{(B) Optimal visualization of paint changes and sketches in Picasso's The Tragedy}

Infrared reflectography is used in conservation to reveal preparatory sketches and paint changes in paintings. The method involves broad spectral band imaging of the painting in the 900 to $\sim 1800 \mathrm{~nm}$ spectral region [1]. In this spectral region, the majority of artists' paints used absorb less and scatter less, which allows penetration of the paint layer. However, prior spectral imaging studies have shown that the optimal spectral window to visualize such features varies with the material used as well as the thickness of the paint layer [1]. Moreover, the visualization of paint changes requires incomplete penetration of the paint layers. It is anticipated that for complex and heavily reworked paintings, the optimal spectral region to visualize such changes will vary in the SWIR. Hyperspectral images in the SWIR of Picasso's The Tragedy (Fig. 5) were collected to look for such effects. 


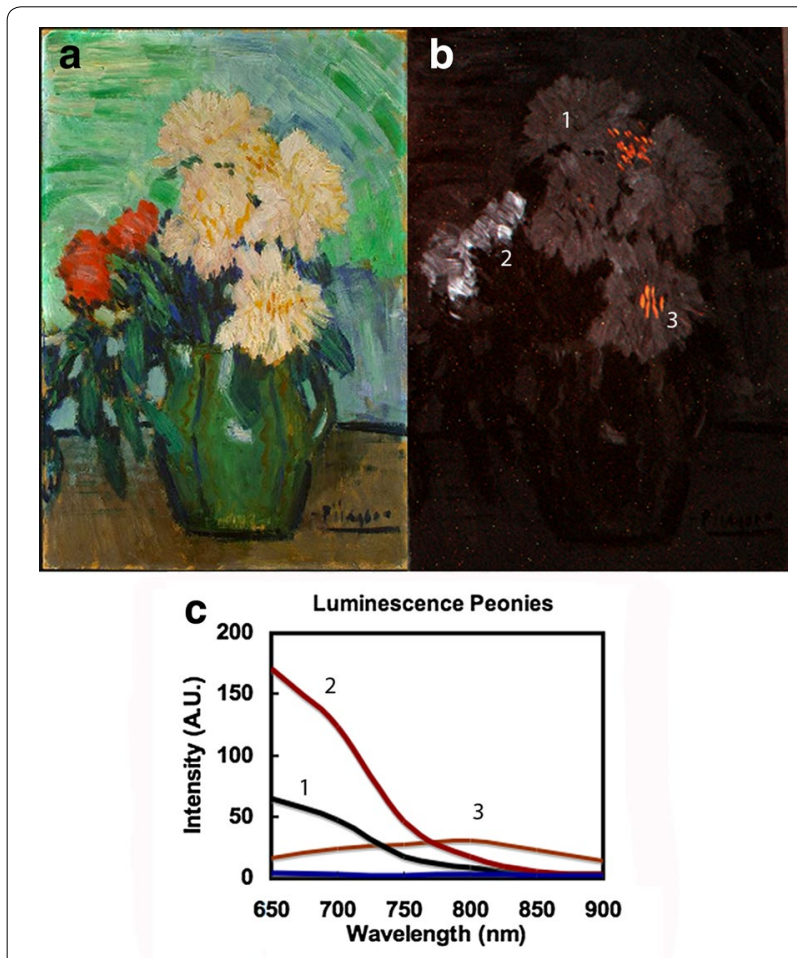

Fig. 4 Results from luminescence imaging spectroscopy of Picasso's Peonies. a Color image. b False-color luminescence image, with the 800,750 , and $700 \mathrm{~nm}$ spectral band images assigned to the R, G, and B color channels. c Plot of luminescence spectra obtained from three labeled sites in the cube

The Tragedy is known to have several compositions beneath the final painting based on results from broadband infrared reflectography [24]. Examination of the 85-band SWIR image cube reveals that the hidden paint changes and drawings can be best viewed if narrow regions of the cube are displayed. For example, optimal visualization of the thick drawing used for the final figures has maximal contrast at approximately $1200 \mathrm{~nm}$ (Fig. 6a). This is shown by the difference in reflectance between pixels centered over the drawing material versus pixels adjacent to the drawing material. The maximum difference in reflectance is $\sim 20 \%$. Thus, the false-color images that span the spectral region where the reflectance intensity differences are the greatest (i.e. the optimal spectral band) are less likely to be cluttered with other painted features.

Similarly, the 'dying horse', which is under the final composition and is reminiscent of earlier Picasso bullfight scenes [24], is optimally visualized at $1350 \mathrm{~nm}$ (Fig. 6b). Here the maximum reflectance difference is less than $5 \%$, and the optimal spectral range is narrower. The false-color image shows not only the paint used to model the horse, but also the drawing lines used to delineate

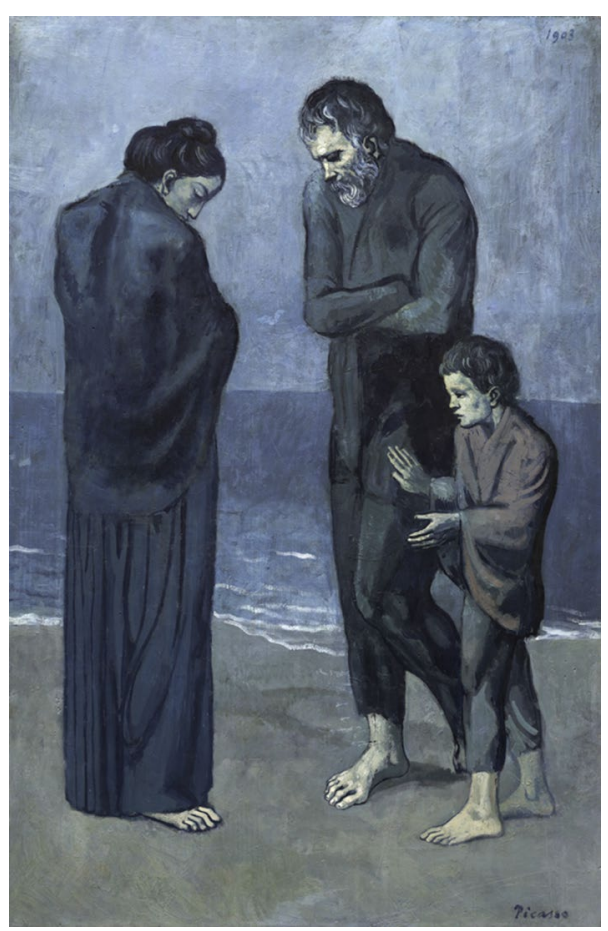

Fig. 5 Color image of Picasso's The Tragedy (1903). Chester Dale collection, 1963.10.196, National Gallery of Art, Washington, DC

the horse's features. Finally, at approximately $1500 \mathrm{~nm}$, all the paint is penetrated and the extensive drawings of caricatures drawn directly on the wood panel are best visualized (Fig. 6c). In addition, the wood grain can be seen clearly near $1600 \mathrm{~nm}$, indicating that no ground is present on the panel. Prior broadband infrared images revealed many of these features, however, they were difficult to discern because of the low signal-to-noise ratio of the detector and the multitude of images present [24]. Therefore, the combination of narrow band, false-color composite images and being able to view the reflectance spectra improves the ability to emphasize features of interest when compared to the earlier broadband methodology where a single infrared reflectogram image was produced.

\section{(C) Mapping conservation fill below the surface of a late 13th century panel painting}

In addition to mapping and identifying pigments, and visualizing composition changes below the surface of artworks, reflectance imaging spectroscopy can also be used to distinguish regions of non-original material. Reflectance imaging spectroscopy in the SWIR region was performed on a late 13th century panel painting entitled Maestà (Madonna and Child with Four Angels) by a follower of Duccio di Buoninsegna. In Fig. 7b, a broadband 

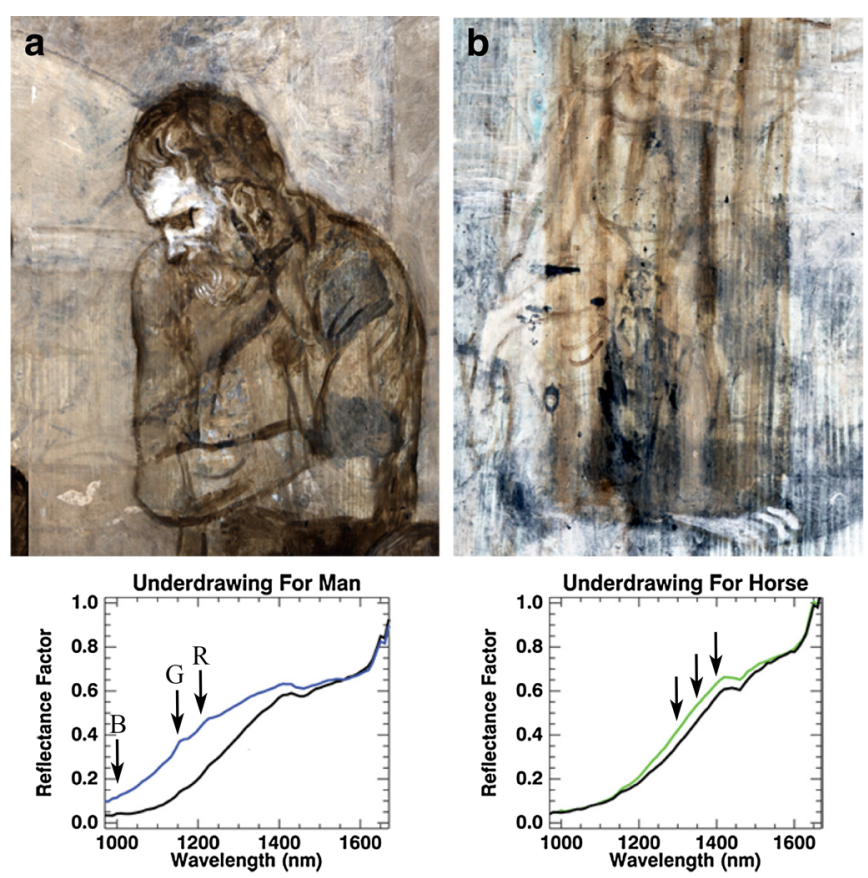
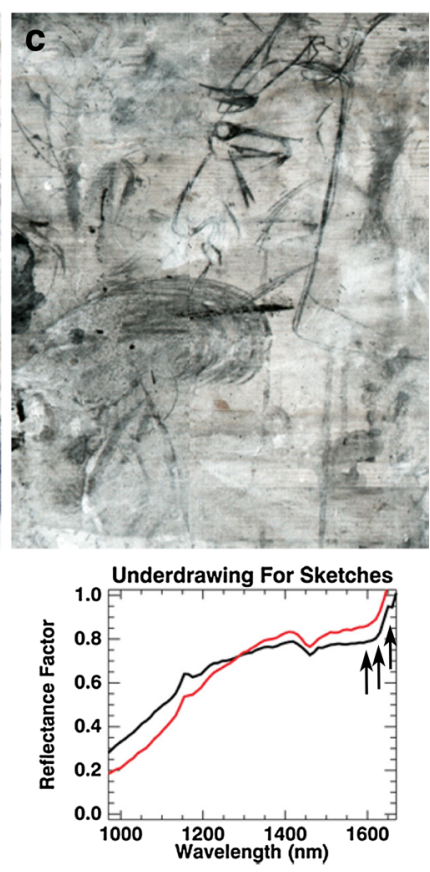

Fig. 6 Results from shortwave infrared reflectance imaging spectroscopy of Picasso's The Tragedy (1903). False-color infrared reflectograms of three detail sections from The Tragedy (top row of $\mathbf{a}, \mathbf{b}$, and $\mathbf{c}$ ). Each image shows a selection of the three spectral band images that best reveal the various underdrawings and caricatures on the panel. Reflectance spectra (bottom row of $\mathbf{a}, \mathbf{b}$, and $\mathbf{c}$ ) taken of adjacent sites that are directly over or right next to an underdrawing line are displayed below their corresponding image

infrared reflectogram (1000-1700 $\mathrm{nm})$ shows a detail of one of the angel's faces. In the face region, there are similar gray levels, indicating the average reflectance from 1000 to $1700 \mathrm{~nm}$ is similar across the facial region. This monochrome image provides limited material information. Figure 7c shows a false-color image generated from hyperspectral reflectance data, where the 1650, 1400, and $1050 \mathrm{~nm}$ spectral band images are placed in the red, green, and blue color channels, respectively. From this image, distinct material differences are apparent in the face. The area between and under the eyes appears as blue-gray in the false-color image and is likely a fill applied by a restorer to cover an existing loss. A spectrum from this region (Fig. 7d) shows a slow increase in reflectance from 1000 to $1700 \mathrm{~nm}$ with a sharp absorption feature near $1415 \mathrm{~nm}$, which is consistent with talc [21], a common filler in paints. The face region that appears brown in the false-color image shows some of the brushstrokes that are likely associated with verdaccio, a greenish underpainting consisting of a mixture of earth and black pigments that serves as a tonal guide for the subsequent application of color [25]. This region is likely original to the artwork, and the reflectance spectrum from this region (shown in black) supports this hypothesis. The more intense absorptions below $1200 \mathrm{~nm}$ are likely from the dark earth and black pigments, whereas the discrete absorption features near 1450, 1490, and $1535 \mathrm{~nm}$ are indicative of gypsum, commonly used as a ground in Italian panel paintings.

\section{Conclusions}

These results from reflectance and luminescence imaging spectroscopy show the ability of in situ methods to map and identify many of the primary pigments used in paintings. This pigment identification method is made more robust when combined with site-specific analysis methods such as XRF. Also highlighted is the utility of reflectance imaging spectroscopy in the SWIR region to better reveal specific paint changes, including changes in the drawings and markings made by the original artist, or changes made by a subsequent conservator such as a fill. Imaging spectroscopy is one of several emerging 

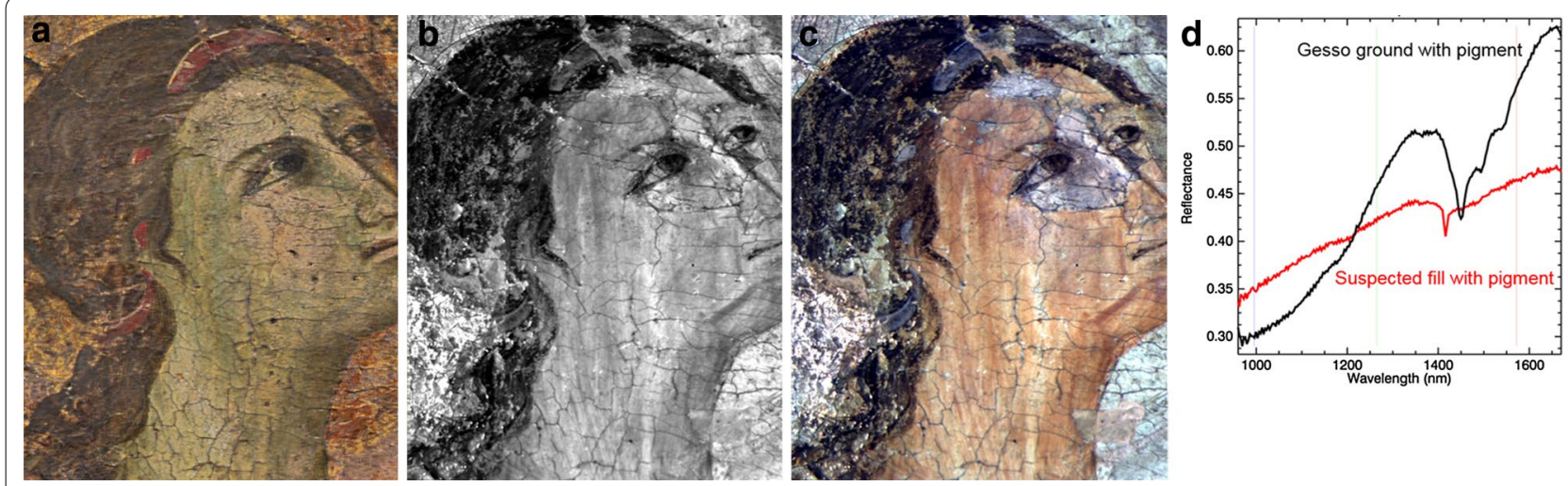

Fig. 7 Detail images from Madonna and Child with Four Angels, c. 1290. Samuel H. Kress Collection, 1961.9.77, National Gallery of Art, Washington, DC. a Color detail. b Detail from broadband infrared reflectogram (1000 to $1700 \mathrm{~nm}$ ) which provides little material information. c False-color image $(R=1650 \mathrm{~nm}, G=1400 \mathrm{~nm}, \mathrm{~B}=1050 \mathrm{~nm})$ showing distinct material differences. The region under the eyes is likely a conservation fill and corresponds with the red spectrum in (d) that has a strong absorption at $\sim 1415 \mathrm{~nm}$, possibly talc. The brown regions in the false-color image show brushstrokes likely associated with verdaccio, an underpainting that is probably original to the artwork. This region corresponds with the black spectrum whose absorption between 1450 and $1550 \mathrm{~nm}$ indicates the presence of gypsum

mapping and imaging tools likely to play an important role in advancing our understanding of polychrome works of art.

\section{Authors' contributions}

$J K D, M T, J Z, P R$, and KD collected the reflectance and fluorescence imaging spectroscopy data and completed data analysis. KM and MT completed XRF data collection and analysis. The manuscript was written and edited by JD, KD, and PR. All authors read and approved the final manuscript.

\section{Author details}

${ }^{1}$ National Gallery of Art, 4th and Constitution Avenue NW, Washington, DC 20565, USA. ${ }^{2}$ Night Vision and Electronic Sensors Directorate, 10221 Burbeck Rd, Fort Belvoir, VA 22060, USA. ${ }^{3}$ Present Address: IPANEMA USR3461 CNRS/ MCC, chez Synchrotron SOLEIL, BP 48, St Aubin, 91192 Gif Sur Yvette, France. ${ }^{4}$ Present Address: The Fitzwilliam Museum, Trumpington St, Cambridge CB2 IRB, UK.

\section{Acknowledgements}

The authors thank Elizabeth Walmsley, Ann Hoenigswald, and Joanna Dunn (NGA) for technical advice on interpreting the infrared images and Dr. Roy Littleton and Tyler Anderson (NVESD) for technical support during data collection. The authors acknowledge financial support from the National Science Foundation (award 1041827), and J.K.D. acknowledges support from the Andrew W. Mellon and the Samuel H. Kress Foundations.

\section{Competing interests}

The authors declare that they have no competing interests.

Received: 11 November 2015 Accepted: 28 February 2016

Published online: 16 March 2016

\section{References}

1. Walmsley E, Metzger C, Delaney JK, Fletcher C. Improved visualization of underdrawings with solid-state detectors operating in the infrared. Stud Conserv. 1994:39:217-31.

2. Casini A, Bacci M, Cucci C, Lotti F, Porcinai S, Picollo M, Radicati B, Poggesi M, Stefani L. Fiber optic reflectance spectroscopy and hyper-spectral image spectroscopy: two integrated techniques for the study of the Madonna dei Fusi. Proc SPIE. 2005;5857:177-84.
3. Dirk CW, Delgado MF, Olguin M, Druzik J. A prism-grating-prism spectral imaging approach. Stud Conserv. 2009;54:77-89.

4. Delaney JK, Zeibel JG, Thoury M, Littleton R, Palmer M, Morales KM, de la Rie ER, Hoenigswald A. Visible and infrared imaging spectroscopy of Picasso's Harlequin Musician: mapping and identification of artist materials in situ. Appl Spectrosc. 2010;64:584-94.

5. Thoury M, Delaney JK, de la Rie ER, Palmer M, Morales K, Krueger J. Nearinfrared luminescence of cadmium pigments. In situ identification and mapping in paintings. Appl Spectrosc. 2011;65:939-51.

6. Dik J, Janssens K, Van Der Snickt G, van der Loeff L, Rickers K, Cotte M. Visualization of lost painting by Vincent Van Gogh using synchrotron radiation based X-ray fluorescence elemental mapping. Anal Chem. 2008;80:6436-42.

7. Clark RN. Spectroscopy of rocks and minerals, and principles of spectroscopy. In: Rencz AN, editor. Manual of remote sensing, remote sensing for the earth sciences, vol. 3. New York: Wiley; 1999. p. 3-58.

8. Bacci M, Picollo M. Non-destructive spectroscopic detection of cobalt (II) in paintings and glass. Stud Conserv. 1996;41:129-35.

9. Picollo M, Bacci M, Magrini D, Radicati B, Trumpy G, Tsukada M, Kunzelman D. Modern white pigments: their identification by means of noninvasive ultraviolet, visible, and infrared fiber optic reflectance spectroscopy. In: proceedings of the Conference Modern Paints Uncovered. 2007. p. 118-28.

10. Delaney JK, Walmsley E, Berrie BH, Fletcher CF. Scientific examination of art-modern techniques in conservation and analysis. Washington: The National Academies Press; 2005. p. 120-36.

11. Bacci M, Magrini D, Picollo M, Vervat M. A study of the blue colors used by Telemaco Signorini (1835-1901). J Cult Heritage. 2009;10:275-80.

12. de la Rie ER. Fluorescence of paint and varnish layers (part III). Stud Conserv. 1982;27:102-8.

13. de la Rie ER. Fluorescence of paint and varnish layers (part I). Stud Conserv. 1982;27:1-7.

14. Vagnini M, Miliani C, Cartechini L, Rocchi P, Brunetti BG, Sgamellotti A. FTNIR spectroscopy for non-invasive identification of natural polymers and resins in easel paintings. Anal Bioanal Chem. 2009;395:2107-18.

15. Ricciardi P, Delaney JK, Facini M, Zeibel JG, Picollo M, Lomax S, Loew M. Near infrared reflectance imaging spectroscopy to map paint binders in situ on illuminated manuscripts. Angew Chem Int Ed. 2012;51:5607-10.

16. Dooley KA, Lomax S, Zeibel JG, Miliani C, Ricciardi P, Hoenigswald A, Loew M, Delaney JK. Mapping of egg yolk and animal skin glue paint binders in Early Renaissance paintings using near infrared reflectance imaging spectroscopy. Analyst. 2013;138:4838-48.

17. Glinsman LD. The application of $x$-ray fluorescence spectrometry to the study of museum objects. University of Amsterdam, Department of Chemistry; 1990. 
18. Delaney JK, Ricciardi P, Glinsman LD, Facini M, Thoury M, Palmer M, de la Rie ER. Use of imaging spectroscopy, fiber optic reflectance spectroscopy and $\mathrm{X}$-ray fluorescence to map and identify pigments in illuminated manuscripts. Stud Cons. 2014;59(2):91-101.

19. Alfeld M, Janssens K, Dik J, de Nolf W, van der Snickt G. Optimization of mobile scanning macro-XRF systems for the in situ investigation of historical paintings. J Anal At Spectrom. 2011;26:899-909.

20. Boardman JW, Kruse FA, Green RO. Mapping Target Signatures via Partial Unmixing of AVIRIS Data. In: Realmuto VJ, editor. Summaries of the fifth annual JPL Airborne Earth Science Workshop, vol. 1. Washington: JPL; 1995. p. 23-6.

21. Clark RN, Swayze GA, Wise R, Livo E, Hoefen T, Kokaly R, et al. USGS digital spectral library splib06a. Denver: US Geological Survey, Digital Data Series
231. http://speclab.cr.usgs.gov/spectral.lib06/ds231/index.html. Accessed 22 Dec 2012.

22. CNR-IFAC. Fiber optics reflectance spectra database of pictorial materials in the 270-1700 nm Range accessed 22 December 2012. [http://fors.ifac. cnr.it/].

23. Morales K. Request Number: 824. National Gallery of Art: Scientific Research Department Internal Report; 2008.

24. Hoenigswald A. Works in Progress: Pablo Picasso's Hidden Images. In: Picasso The Early Years, 1892-1906. Washington: The National Gallery of Art; 1997. p. 299-309.

25. Dunn JR, Berrie BH, Delaney JK, Glinsman LD. The creation of Giotto's Madonna and Child: new insights, FACTURE, vol. 2. New Haven: Yale Press. 2015. p. 2-17.

\section{Submit your manuscript to a SpringerOpen ${ }^{\circ}$ journal and benefit from:}

- Convenient online submission

- Rigorous peer review

- Immediate publication on acceptance

- Open access: articles freely available online

- High visibility within the field

- Retaining the copyright to your article

Submit your next manuscript at $>$ springeropen.com 